ORIGINAL ARTICLE

\title{
"Bounce at the Bell": a novel program of short bouts of exercise improves proximal femur bone mass in early pubertal children
}

\author{
H A McKay, L MacLean, M Petit, K MacKelvie-O'Brien, P Janssen, T Beck, K M Khan
}

Br J Sports Med 2005;39:521-526. doi: 10.1136/bjsm.2004.014266

See end of article for authors' affiliations

....................

Correspondence to: H A McKay, University of British Columbia, 588-828 West 10th Ave,

Vancouver, BC, Canada

V52 1L8; mckayh@

interchange.ubc.ca

Accepted

21 December 2004
Objectives: To examine the effects of a simple and inexpensive physical activity intervention on change in bone mass and structure in school aged children.

Methods: Fifty one children ( $\mathrm{n}=23$ boys and 28 girls; mean age 10.1 years) participated in "Bounce at the Bell" which consisted of 10 counter-movement jumps $3 \times$ per day (total $\sim 3 \mathrm{~min} /$ day). Controls were 71 matched children who followed usual school practice. We assessed dietary calcium, physical activity, physical performance, and anthropometry in September and after 8 months of intervention (June). We measured bone mineral content (BMC) and bone area at the lumbar spine, total body, and proximal femur. Proximal femur scans were also analysed for bone geometry and structural strength using the hip structural analysis program. Lean and fat mass $(\mathrm{g})$ were also calculated.

Results: Groups were similar at baseline and did not differ in weight, height, total body, lumbar spine, proximal femur, or femoral neck BMC. Control children had a greater increase in adjusted total body BMC (1.4\%). Intervention children gained significantly more BMC at the total proximal femur $(2 \%)$ and the intertrochanteric region (27\%). Change in bone structural parameters did not differ between groups. Conclusions: This novel, easily implemented exercise program, took only a few minutes each day and enhanced bone mass at the weight bearing proximal femur in early pubertal children. A large, randomised study of boys and girls should be undertaken powered to test the effectiveness of Bounce at the Bell in children at different stages of maturity, and in boys and girls independently.
U pwards of $90 \%$ of adult bone mass is acquired by the end of adolescence, ${ }^{1-5}$ and evidence is accumulating that appropriate mechanical loading (for example, various forms of exercise) can modify the mass, geometry, and structural strength of the skeleton during the growing years. ${ }^{16}$ The precise timing of the exercise intervention to augment bone parameters appears to be important as Kannus and colleagues reported a 2.5 times greater benefit from racquet sports begun in premenarche compared with the same activity begun after menarche. ${ }^{7}$ It has been noted that early puberty, when appendicular growth is more rapid than axial growth, could be an opportune time to build a stronger skeleton. ${ }^{8} 9$ Indeed, exercise interventions in postmenarcheal girls have not proven as osteogenic as those begun in premenarche. ${ }^{6}$

Our understanding of bone's response to mechanical loading has been hampered in part by the lack of available instruments to measure bone geometry and structural strength. The most commonly reported bone outcomes are bone mineral content (BMC, g) and areal bone mineral density (aBMD, $\left.\mathrm{g} / \mathrm{cm}^{2}\right)$. aBMD is merely a surrogate of bone strength and does not represent a specific measure of mechanical strength. Growing bone can adapt to improve its strength by increasing periosteal dimensions or by reducing endosteal expansion, in addition to adding mass. These geometric changes may not be apparent in traditional measures of aBMD or BMC. ${ }^{10}$ We previously assessed changes in proximal femur bone geometry and structural strength that accompanied increased BMC with our Healthy Bones II intervention. Both boys and girls partaking in this school based intervention increased bone mass and bone bending strength (measured by section modulus, a mechanical measure of bending strength) after $8^{11-13}$ or $20^{14}{ }^{15}$ months of intervention. ${ }^{16}$
Although our previous interventions were implemented within the school curriculum, they involved some equipment (steps, jump ropes, etc) and needed 10-20 min 3×/week during the school day. ${ }^{12} 17$ Other interventions in children required 20-90 min after school and/or specially trained teachers. ${ }^{18-20}$ For a school based program that targets the growing skeleton to gain acceptance on a population-wide basis, it must be effective, simple to administer, possible to perform in the classroom, hallway, or schoolyard, short in duration, and inexpensive. Promising data from young animals indicated that short, discrete bouts of exercise administered with rest inserted between loading bouts, were more effective than a single longer bout of exercise for improving bone mass and strength. ${ }^{21}$ These experimental data showed that mechanosensitivity of bone declined quickly after initiation of a loading bout and that only a few bouts of loading per session were required to optimise the osteogenic response. ${ }^{21} 22$ To our knowledge, no such intervention has yet been assessed in children.

Based on this advance in understanding of bone biology in animals, we conducted an 8 month controlled trial of a very simple, inexpensive, and easily to implement intervention comprised of short bouts of activity ("Bounce at the Bell") interspersed throughout the school day. The intervention required only $\sim 3 \mathrm{~min} /$ day to complete and was implemented

Abbreviations: $a B M D$, areal bone mineral density; $A N C O V A$, analysis of covariance; ANOVA, analysis of variance; BA, bone area; BMC, bone mineral content; BW, body weight; CSA, cross-sectional area; CSMI, cross-sectional moment of inertia; DXA, dual energy $x$ ray absorptiometry; FFQ, food frequency questionnaire; $F N$, femoral neck; FS, femoral shaft; GT, greater trochanter; HSA, hip structural analysis; IT, intertrochanter; LS, lumbar spine; NN, narrow neck; PAQ-C, Physical Activity Questionnaire for Children; PF, proximal femur; UBC, the University of British Columbia 
with no equipment, by generalist teachers, and within the classroom. Our objective was to examine the effects of this intervention on change in bone mass and geometry in grade 4 and 5 children, and to compare outcomes to our previous Healthy Bones intervention trials.

\section{METHODS}

Data collection procedures were the same as described in our previous reports ${ }^{11}{ }^{14-16}$ and are summarised below. All measurements took place in the University of British Columbia (UBC) Bone Health Research Laboratory in Vancouver, and the Bounce at the Bell exercise program (detailed below) was conducted within intervention schools.

\section{Design and participants}

Bounce at the Bell was a prospective cohort study. We recruited three schools in the Richmond School District to undertake the 8 month (l school year) intervention. Participants were measured at baseline (start of the school year, September) and after 8 months (end of the school year, June). Fifty one children in grade 4 or 5 intervention classrooms consented to participate and were measured at the UBC Bone Health Research laboratory. All 51 children in the intervention group returned for follow up measurement at the end of the school year.

Our control group was comprised of children matched for race, sex, height, and maturity who attended Healthy Bones II control schools, also in the Richmond School District. The Healthy Bones II trial was completed 1 year prior to the current study and evaluated the effect of a 20 month, physical education based exercise intervention on bone mass in pre and early pubertal boys and girls. ${ }^{11}{ }^{12}{ }^{14-16}$ If two control participants met the matching criteria, both were included in the analyses. Thus, 73 children served as controls for the 51 intervention children and groups were comprised of a similar percentage of boys and girls, Asian and Caucasian, and equivalent-maturity level children. Richmond is comprised of a population approximately 34\% Hong Kong Chinese, 57\% North American/Western European Caucasian, 5\% Southeast Asian, and $4 \%$ other ethnic origin or mixed ethnicity. The UBC Clinical and Behavioural Sciences Research Ethics committee and the Richmond School Boards approved the study.

\section{Bounce at the Bell intervention}

Bounce at the Bell was simple to administer and perform, short in duration (requiring approximately $3 \mathrm{~min} /$ day), and inexpensive. The program was carried out in the elementary school classroom with no equipment and required only minimal training of generalist (rather than physical education) teachers.

We provided teachers in intervention schools with an instruction booklet that illustrated counter-movement jumps. A research assistant met the teachers three times throughout the school year to observe, demonstrate, and review the jumps. Teachers instructed the children to perform 10 counter movement jumps (two foot take off, clutch knees, two foot landing), three times each school day (once at morning bell, once at noon bell, and once at home time bell). Ground reaction forces for a counter movement jump were five times body weight (BW) and maximum rate of force was $>400 \mathrm{BW} / \mathrm{s}$ in an independent sample of 70 boys and girls ${ }^{23}$ measured in the UBC Biomechanics Laboratory. Teachers maintained a record of student attendance and the average number of jumps the class performed each day. Records were collected at the school visits. Both intervention and control schools partook of physical education as mandated by their school board $(2 \times 40 \mathrm{~min}$ classes per week, on average $)$.

\section{Measurements}

\section{Health history}

Parent(s) completed a health history questionnaire for their child and all healthy children from whom we obtained parental consent were eligible to participate. None of the children in the study were taking medications or had any disease known to influence bone metabolism.

\section{Descriptive variables}

Maturity was rated (1-5) against Tanner breast (girls) and pubic hair (boys) line drawings. ${ }^{24}$ Children were either assisted by a member of the research team with each follow up assessment, or completed a maturity assessment with written instructions (in English or Chinese) under parental supervision at home. We used the mean of two measures of stretch stature for sitting and standing height $(\mathrm{mm})$ and BW $(\mathrm{kg})$. Sitting height was subtracted from standing height to estimate leg length $(\mathrm{mm}) .{ }^{11}$ We report the mean of two calf girth $(\mathrm{cm})$ measures, assessed at the site of maximal girth using a metal tape measure. We assessed vertical jump (to the nearest $\mathrm{mm})^{25}$ to represent dynamic power.

Questionnaires, as per our previous trials, ${ }^{11}{ }^{12}$ 14-16 were administered three times during the school year (autumn, winter, spring) to assess dietary intake of calcium and participation in physical activity outside the intervention. We used the average of these three values for analyses. The calcium food frequency questionnaire (FFQ) has been validated in Asian and Caucasian children. ${ }^{17}{ }^{26}$ A bilingual (Chinese-English) trained measurer assisted non-English speaking Chinese children. Physical activity during the previous 7 days was determined by a modified version of the Physical Activity Questionnaire for Children (PAQ-C). ${ }^{27}$ General physical activity scores were calculated as an average of the PAQ-C items, in a continuous range between 1 (low activity) and 5 (high activity) and as estimated minutes per week. ${ }^{28}{ }^{29}$ We modified the PAQ-C to include an estimate of time spent in loaded physical activity and the number of nights of extracurricular sports activities/week. ${ }^{11}{ }^{12}$

\section{Bone mineral content and bone area}

We used a Hologic QDR $4500 \mathrm{~W}$ bone densitometer (DXA) to assess bone mass and area. BMC $(\mathrm{g})$ and bone area (BA, $\left.\mathrm{cm}^{2}\right)$ were measured for total body, lumbar spine (LS), and proximal femur (PF). Proximal femur scans were analysed for the femoral neck (FN), and greater trochanteric (GT) and intertrochanteric (IT) subregions. Two trained and qualified technicians acquired all scans. Scans were analysed using standardised procedures ${ }^{30}$ by one researcher (LM). Total body lean mass and fat mass ( $\mathrm{g}$ ) were obtained from total body DXA scans. Our precision values and quality assurance procedures for densitometry are reported elsewhere. ${ }^{11}$

\section{Hip structural analysis}

We applied the hip structural analysis (HSA) program ${ }^{13} 1531$ to proximal femur DXA scans to evaluate bone geometry and estimate structural strength at the narrow neck (NN) and femoral shaft (FS) regions of the proximal femur. The HSA program locates the axes of the femoral neck and shaft from the bone mineral image and then derives structural geometry from profiles of pixel value along lines orthogonal to the bone axis at specific points. Profiles of bone mass from each region are used to derive aBMD $\left(\mathrm{g} / \mathrm{cm}^{2}\right)$ directly as the average value. Bone cross-sectional area (CSA) is derived as the integral of the profile of pixel values converted to centimetres and subperiosteal width is the blur corrected width of the profile. Cross-sectional moment of inertia (CSMI) is derived as the integral of pixel area times the square of distance from the profile centroid. The section modulus ( $Z$ ), a determinant of bending strength, is computed as $\mathrm{Z}=\mathrm{CSMI} /$ (maximum 
distance from centre of mass to outer cortical margin). Like BMC, CSA measures the amount of bone within the crosssection but expresses the quantity in terms of cortical equivalent surface area rather than mineral mass.

The fan beam mode of the QDR 4500 produces an error in pixel spacing along the fan beam direction that varies with the height of the bone above the scanner table surface. A special calibration phantom was used to quantify the height effect with a pair of identical copper foils at different (known) distances above the tabletop. This yielded a correction for pixel spacing as a function of the height of the bone. Based on computerised tomography observations, the proximal femur is located at approximately the midsagittal plane at the level of the hip. Bone height was estimated for each scan as one half of the average soft tissue thickness derived from attenuation data in the hip region.

\section{Statistical analyses}

We used analysis of variance (ANOVA) to compare baseline bone, anthropometry, dietary calcium, performance, and physical activity variables between intervention and control groups. To compare change in $\mathrm{BA}, \mathrm{BMC}$, and bone structure between groups, we used a $2(\operatorname{sex}) \times 2$ (group) analysis of covariance (ANCOVA, SPSS GLM procedure). We also used ANOVA (sex by group) to compare 8 month change in anthropometry, dietary calcium, performance, and physical activity variables. We report absolute change (final-baseline) (table 1), adjusted change (table 2), and adjusted per cent change [( (final-baseline $) /$ baseline $) \times 100]$ (text) for bone mass and structure variables. As in previous studies, we controlled for baseline bone value and weight, change in height, and final maturity stage to account for the well known variability in growth and change in growth parameters for children of a similar chronological age. We also controlled for physical activity load time to account for group differences at baseline $(p=0.076)$. Data were analysed with SPSS version 11.0 and significance was set at $\mathrm{p}<0.05$.

\section{RESULTS}

\section{Compliance}

Compliance ranged from 10 jumps three times per day, 2 days per week, to 10 jumps three times per day 5 days per week with a mean uptake of $90 \pm 34$ jumps per week. Average school attendance of the intervention children was $96.8 \%$ ranging from 0 to 25 days absent (excluding statutory and school holidays).

\section{Descriptive characteristics}

Fifty one children participated in the intervention $(n=23$ boys and 28 girls). Control children who met the matching criteria for sex, height, and maturity were 36 boys and 39 girls, thus 24 children had a 2:1 match. Age ranged from 8.9 to 10.8 years at baseline for the intervention group and from 9.2 to 11.0 years for the control group. Control and intervention children matched on maturity were Tanner 1 $(65 \%), 2(33 \%)$, or $3(2 \%)$ at baseline. At follow up, $36 \%$ of control and $25 \%$ of intervention children were Tanner stage 1 , 53 and 56\% were Tanner stage 2, and 11 and 15\% were Tanner stage 3 . One intervention boy reported advancing from Tanner stage 1 to Tanner stage 4.

There were $38 \%$ Caucasian, $48 \%$ Asian, and 15\% other (including mixed ethnic, Black, and South Asian) children in both the control and intervention groups. Baseline values and 8 month change for anthropometry, performance variables, dietary calcium, and physical activity are presented (table 1). There were no significant differences between intervention and control groups at baseline or for change with the exception of a significantly greater increase in calf girth in the intervention children $(1.9 \vee 3.8 \%, \mathrm{p}=0.002)$.

\section{Bone mineral content and bone area}

Baseline (table 1) and 8 month change (table 2) in BMC and BA by DXA are presented. There were no differences between intervention and control groups at baseline for any bone variables. Control children demonstrated a significantly greater increase in adjusted total body BA (7.5 $v 6.3 \%$, $\mathrm{p}=0.004)$ and total body BMC (10.1 $v 8.7 \%, \mathrm{p}=0.036)$ over the study period (table 2). However, the intervention group gained significantly more BMC at the loaded total proximal femur $(14.4 v 12.3 \%, \mathrm{p}=0.019)$ (table 2, fig 1$)$. This group difference was accounted for by a significantly greater increase in intertrochanteric BMC in the intervention group compared with controls ( $14.4 \vee 11.7 \%, \mathrm{p}=0.017)$. Adjusted $\mathrm{BA}$ at the total proximal femur $(+1.3 \%, \mathrm{p}=0.072)$ and intertrochanteric region $(+2.0 \%, \mathrm{p}=0.065)$ also increased more (NS) in intervention children.

\section{Sex difference in response}

There were no significant sex $\times$ group interactions for change in bone variables. There was, however, a trend for the bone response to be greater in boys at all regions of the proximal femur with the exception of the femoral neck. Intervention boys increased BMC by 3.1, 4.0, and 4.2\% more than controls at the PF, IT, and GT regions, respectively. In contrast, girls in

Table 1 Baseline and change (where relevant) in descriptive characteristics for intervention and control groups

\begin{tabular}{|c|c|c|c|c|c|c|}
\hline & \multicolumn{2}{|l|}{ Baseline } & \multirow[b]{3}{*}{$\mathbf{p}$} & \multicolumn{2}{|c|}{8 month change } & \multirow[b]{3}{*}{$\mathbf{p}$} \\
\hline & \multirow{2}{*}{$\begin{array}{l}\text { Control } \\
n=73\end{array}$} & \multirow{2}{*}{$\begin{array}{l}\text { Intervention } \\
n=51\end{array}$} & & \multirow{2}{*}{$\begin{array}{l}\text { Control } \\
n=73\end{array}$} & \multirow{2}{*}{$\begin{array}{l}\text { Intervention } \\
n=51\end{array}$} & \\
\hline & & & & & & \\
\hline Age, years & $10.2 \pm 0.43$ & $10.1 \pm 0.5$ & 0.15 & & & \\
\hline Height, cm & $140.4 \pm 6.0$ & $139.8 \pm 7.0$ & 0.59 & $4.0 \pm 1.2$ & $4.3 \pm 1.3$ & 0.14 \\
\hline Sitting height, $\mathrm{cm}$ & $74.4 \pm 3.5$ & $73.9 \pm 3.8$ & 0.38 & $1.7 \pm 1.4$ & $1.9 \pm 0.9$ & 0.53 \\
\hline Leg length, cm & $65.9 \pm 3.3$ & $65.8 \pm 3.6$ & 0.83 & $2.3 \pm 1.4$ & $2.6 \pm 1.3$ & 0.16 \\
\hline Weight, kg & $35.1 \pm 8.0$ & $35.7 \pm 9.1$ & 0.73 & $2.8 \pm 1.5$ & $2.6 \pm 2.0$ & 0.34 \\
\hline Fat mass, kg & $8.9 \pm 5.0$ & $8.9 \pm 4.9$ & 0.95 & $6.7 \pm 10.5$ & $6.7 \pm 13.5$ & 0.98 \\
\hline Lean mass, kg & $26.1 \pm 4.0$ & $25.3 \pm 4.6$ & 0.32 & $21.6 \pm 10.2$ & $22.1 \pm 10.4$ & 0.15 \\
\hline Calf girth, $\mathrm{cm}$ & $29.0 \pm 2.8$ & $28.8 \pm 3.2$ & 0.66 & $0.6 \pm 1.1$ & $1.1 \pm 0.7^{*}$ & 0.002 \\
\hline Vertical jump & $23.5 \pm 5.6$ & $23.4 \pm 6.1$ & 0.93 & $3.2 \pm 4.0$ & $3.6 \pm 4.3$ & 0.59 \\
\hline Calcium, mg/day† & $832 \pm 380$ & $821 \pm 377$ & 0.88 & & & \\
\hline Physical activity score $†$ & $3.0 \pm 0.5$ & $3.0 \pm 0.6$ & 0.73 & & & \\
\hline $\begin{array}{l}\text { Physical activity load time, } \uparrow \\
\mathrm{min} / \text { week }\end{array}$ & $5.6 \pm 4.3$ & $7.2 \pm 5.9$ & 0.07 & & & \\
\hline
\end{tabular}

†Values were averaged from questionnaires administered three times over the year (autumn, winter, and spring). * Significantly different from control group $(\mathrm{p}<0.01)$. p values refer to change between intervention and control over the study period. Values are mean $\pm S D$. 
Table 2 Baseline and adjusted 8 month change in BMC and area for control $(n=73)$ and intervention $(n=51)$ groups

\begin{tabular}{|c|c|c|c|c|}
\hline & \multicolumn{2}{|c|}{ Baseline, mean (SD) } & \multicolumn{2}{|c|}{8 month change $\ddagger$, mean $(95 \% \mathrm{Cl})$} \\
\hline & Control & Intervention & Control & Intervention \\
\hline \multicolumn{5}{|l|}{ Total body } \\
\hline$B M C, g$ & $1047 \pm 169$ & $1054 \pm 97$ & $106(98-114)$ & $92.7(83-102)^{* *}$ \\
\hline Area, $\mathrm{cm}^{2}$ & $1228 \pm 153$ & $1232 \pm 178$ & $95.6(87.6-103.6)$ & $76.7(66.9-86.5)^{*}$ \\
\hline \multicolumn{5}{|l|}{ Lumbar spine } \\
\hline BMC, $g$ & $24.3 \pm 4.4$ & $24.6 \pm 5.1$ & $2.8(2.5-3.1)$ & $2.6(2.3-3.0)$ \\
\hline Area, $\mathrm{cm}^{2}$ & $38.5 \pm 4.4$ & $39.2 \pm 4.5$ & $2.4(2.2-2.6)$ & $2.3(2.0-2.5)$ \\
\hline \multicolumn{5}{|c|}{ Proximal femur } \\
\hline $\mathrm{BMC}, \mathrm{g}$ & $15.6 \pm 3.2$ & $16.2 \pm 3.4$ & $1.9(1.7-2.1)$ & $2.3(2.1-2.6)^{*}$ \\
\hline Area, $\mathrm{cm}^{2}$ & $22.7 \pm 2.6$ & $23.3 \pm 3.0 \dagger$ & $1.8(1.6-2.0)$ & $2.1(1.8-2.3) \dagger$ \\
\hline \multicolumn{5}{|l|}{ Intertrochanter } \\
\hline $\mathrm{BMC}, \mathrm{g}$ & $10.2 \pm 2.2$ & $10.6 \pm 2.2$ & $1.2(1.0-1.3)$ & $1.5(1.3-1.7)^{*}$ \\
\hline Area, $\mathrm{cm}^{2}$ & $13.6 \pm 1.6$ & $13.95 \pm 1.90$ & $0.90(0.73-1.1)$ & $1.2(1.0-1.4)$ \\
\hline \multicolumn{5}{|c|}{ Greater trochanter } \\
\hline$B M C, g$ & $2.7 \pm 0.8$ & $2.9 \pm 0.9$ & $0.55(0.48-0.61)$ & $0.60(0.52-0.68)$ \\
\hline Area, $\mathrm{cm}^{2}$ & $5.1 \pm 1.1$ & $5.3 \pm 1.2$ & $0.73(0.64-0.82)$ & $0.76(0.65-0.87)$ \\
\hline \multicolumn{5}{|l|}{ Femoral neck } \\
\hline $\mathrm{BMC}, \mathrm{g}$ & $2.6 \pm 0.4$ & $2.7 \pm 0.4$ & $0.195(0.161-0.228)$ & $0.191(0.151-0.231)$ \\
\hline Area, $\mathrm{cm}^{2}$ & $4.0 \pm 0.3$ & $4.0 \pm 0.4$ & $0.156(0.122-0.191)$ & $0.145(0.103-0.187)$ \\
\hline
\end{tabular}

¥All change values are adjusted for baseline bone, baseline weight, final Tanner stage, change in height, and physical activity load time.

Significant group main effect by ANCOVA: ${ }^{*}<<0.02 ;{ }^{* *} p<0.05 ; \uparrow p<0.10$.

the intervention group gained 1.0 and $1.4 \%$ more BMC than controls at the PF and IT regions, and demonstrated equivalent gains at the GT region. For both boys and girls, there was no difference in change between groups at the FN region. Control boys gained 3\% more bone than intervention boys at the spine, while there was no difference for the girls ( sex $\times$ group, $p=0.059$ ).

\section{Hip structural analysis}

Although there were no significant differences between intervention and control groups for change in bone structural variables, the mean difference between groups favoured the intervention group at the femoral neck (table 3). At the narrow neck region, the intervention group had greater gains (NS) in bone section modulus $(+3.3 \%)$ because of increased bone CSA $(+2 \%)$ and cortical thickness $(+1.2 \%)$ with no difference in subperiosteal changes. Although the mean difference between groups favoured the control group at the femoral shaft, these non-significant differences for change were all less than $1.0 \%$.

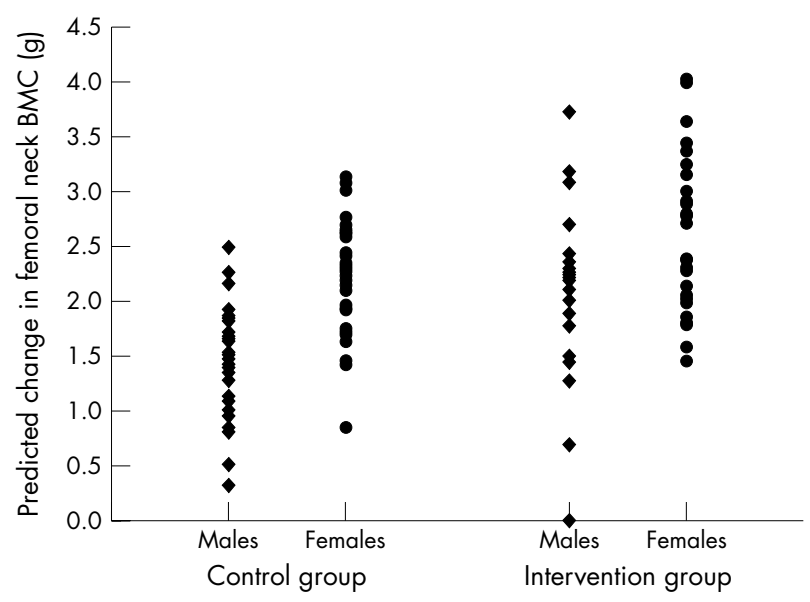

Figure 1 Adjusted \%change in proximal femur (PF) BMC for boys and girls in the intervention and control groups. Boys in the intervention group increased PF BMC 3\% more than control boys, on average, compared with a $1 \%$ greater increase for intervention girls versus control girls. Group $p<0.05$.

\section{DISCUSSION}

\section{A novel intervention}

Over the past decade a number of well designed experimental trials demonstrated that jumping-type exercises during childhood enhanced bone accrual. Although the concept that bone adapts to a dynamic mechanical environment is well established, the minimum effective dose that elicits such a response is not clear. In previous studies, weight bearing exercise programs were implemented either after school for 30-35 min, 3×/week (total: $90 \mathrm{~min} /$ week) $)^{19} 2032$ or during elementary school physical education for $10-15 \mathrm{~min}, 3 \times /$ week (45 min/week). ${ }^{11-14} 1718$ Given the increasing demands on elementary school teachers, and dwindling resources, it is unlikely that these bone health programs would be a feasible addition to an expanding academic curriculum.

Robling et $a l^{21}$ and Umemura's animal experiments ${ }^{22}$ provide the rationale for Bounce at the Bell, a classroom intervention that required a commitment of only a few minutes per day, no additional resources, and minimal training. The present study demonstrated that this novel, simple, and inexpensive program of exercise enhanced bone health during childhood. In addition, Bounce at the Bell was effectively implemented by generalist teachers (not physical education specialists) in the elementary school classroom. Thus, this program could easily be adopted in elementary schools and has the potential to promote childhood bone health on a population-wide basis.

\section{Effectiveness of Bounce of the Bell for augmenting bone mass}

The magnitude of BMC changes in the present study were either greater than or equivalent to the reported gains over 8-10 months in studies that examined either girls or boys at a similar maturational stage (Tanner stages $1-3$ at baseline). ${ }^{1141517-2032}$ As in previous studies, the skeletal response to the Bounce at the Bell intervention was region and site specific. We previously reported significantly greater gains $(\sim 2 \%)$ for LS and FN BMC after 8 months of exercise in early pubertal girls ${ }^{11}$ and for the LS BMC and proximal femur BMD in pre and early pubertal boys. ${ }^{14}$ We have also reported greater gains for trochanteric aBMD in a combined group of younger (8.9 years) prepubertal boys and girls following a more moderate intervention. ${ }^{17}$ Our current findings also agreed with a similar site specific response in Finnish premenarcheal, but not postmenarcheal, girls. ${ }^{32}$ 
Table 3 Baseline and adjusted 8 month change in hip structural analysis (HSA) variables for control $(n=73)$ and intervention $(n=51)$ groups

\begin{tabular}{|c|c|c|c|c|}
\hline & \multicolumn{2}{|c|}{ Baseline, mean \pm SD } & \multicolumn{2}{|c|}{8 month changet, mean $(95 \% \mathrm{Cl})$} \\
\hline & Control & Intervention & Control & Intervention \\
\hline \multicolumn{5}{|l|}{ Narrow neck } \\
\hline $\mathrm{BMD}, \mathrm{g} / \mathrm{cm}^{2}$ & $0.52 \pm 0.06$ & $0.52 \pm 0.06$ & $0.010(0.004-0.017)$ & $0.013(0.006-0.021)$ \\
\hline Bone CSA, $\mathrm{cm}^{2}$ & $1.20 \pm 0.19$ & $1.19 \pm 0.17$ & $0.055(0.036-0.074)$ & $0.069(0.046-0.092)$ \\
\hline Subperiosteal width, $\mathrm{cm}$ & $2.42 \pm 0.18$ & $2.39 \pm 0.20$ & $0.065(0.048-0.082)$ & $0.068(0.047-0.088)$ \\
\hline Section modulus, $\mathrm{cm}^{3}$ & $0.46 \pm 0.10$ & $0.46 \pm 0.09$ & $0.030(0.020-0.041)$ & $0.040(0.027-0.053)$ \\
\hline Endosteal diameter, $\mathrm{cm}$ & $2.23 \pm 0.17$ & $2.19 \pm 0.20$ & $0.061(0.044-0.077)$ & $0.063(0.043-0.083)$ \\
\hline Cortical thickness, $\mathrm{cm}$ & $0.099 \pm 0.01$ & $0.099 \pm 0.01$ & $0.002(0.001-0.003)$ & $0.003(0.001-0.004)$ \\
\hline \multicolumn{5}{|l|}{ Femoral shaft } \\
\hline $\mathrm{BMD}, \mathrm{g} / \mathrm{cm}^{2}$ & $0.62 \pm 0.08$ & $0.62 \pm 0.08$ & $0.029(0.019-0.039)$ & $0.028(0.016-0.041)$ \\
\hline Bone CSA, $\mathrm{cm}^{2}$ & $1.29 \pm 0.20$ & $1.30 \pm 0.22$ & $0.118(0.095-0.141)$ & $0.104(0.075-0.133)$ \\
\hline Subperiosteal width, $\mathrm{cm}$ & $2.18 \pm 0.16$ & $2.20 \pm 0.20$ & $0.093(0.076-0.111)$ & $0.074(0.053-0.096)$ \\
\hline Section modulus, $\mathrm{cm}^{3}$ & $0.53 \pm 0.11$ & $0.54 \pm 0.12$ & $0.068(0.055-0.080)$ & $0.061(0.046-0.076)$ \\
\hline Endosteal diameter, $\mathrm{cm}$ & $1.76 \pm 0.16$ & $1.78 \pm 0.20$ & $0.073(0.053-0.093)$ & $0.055(0.030-0.079)$ \\
\hline Cortical thickness, cm & $0.21 \pm 0.03$ & $0.21 \pm 0.03$ & $0.010(0.006-0.014)$ & $0.010(0.005-0.015)$ \\
\hline
\end{tabular}

†All change values are adjusted for baseline bone structure, baseline weight, final Tanner stage, change in height, and physical activity load time. All non-significant $(p>0.10)$.

\section{What is already known on this topic}

Most adult bone mass is acquired by the end of adolescence and appropriate mechanical loading can modify the mass, geometry, and structural strength of the skeleton during the growing years; the precise timing of exercise to augment bone parameters appears to be important.

\section{Bounce of the Bell and bone structure}

It is important to evaluate structural mechanisms that underpin changes in bone mass by DXA and this study adds valuable data in that regard. The percentage changes between intervention and control groups favoured the intervention group at the narrow neck site by $2 \%$ in CSA and 3.3\% in section modulus. However, due to the relatively small sample size we may have been underpowered to demonstrate the significance of this effect. That said, the clinical relevance of these findings should not be overlooked given that HSA has been shown to be a better predictor of femoral breaking strength than bone mineral density. ${ }^{31}$ These percentage changes are consistent with the significant changes we reported from our 8 and 20 month trials with more traditional exercise interventions in girls ${ }^{13}$ and boys ${ }^{15}$ of similar maturity.

\section{Strengths and limitations of the study}

The key strengths of this study were: (i) the innovative intervention, (ii) the real world classroom setting and program delivery by generalist teachers, and (iii) the evaluation of dependent and independent variables known to be important based on our previous studies. Further, although not a randomised trial, our matched study design aimed to limit known biases in studies of children by ensuring groups were homogeneous for age, sex, race, and maturity. Finally, we evaluated bone structure so as to discern the mechanisms that may underpin bone changes by DXA.

The limitations of the study include the relatively small sample size, thus, we may have had insufficient power to demonstrate an effect of the intervention on bone structure. That said, we were adequately powered to demonstrate an effect of the intervention on BMC, which was our primary outcome variable. Despite matching, intervention children were engaged in marginally (NS) more loaded physical activity at baseline than control children. Although this

\section{What this study adds}

A novel, easily implemented exercise program (Bounce at the Bell) took only a few minutes each day and enhanced bone mass at the weight bearing proximal femur in early pubertal children.

2 min per week more loaded activity is unlikely to affect the outcomes of this study, we controlled for this difference within our analysis. Although DXA derived HSA values provide an important estimate of bone structure, assessing a three-dimensional structure using two-dimensional imaging techniques is challenging. This is especially true in the growing skeleton. The estimates of cortical thickness and endosteal diameter employ assumptions of cross-sectional shape and relative distribution of trabecular and cortical bone within the femoral neck and intertrochanteric cross-sections. These assumptions have not been assessed in children.

\section{SUMMARY}

We have shown that an exercise program that can be easily implemented by elementary school teachers in only a few minutes each day enhances bone mass at the weight bearing proximal femur in participating children. Our results support undertaking a randomised controlled trial of boys and girls powered to test the effectiveness of Bounce at the Bell on bone mass and structure in children of different races and ages and at different stages of maturity.

\section{ACKNOWLEDGEMENTS}

We gratefully acknowledge the principals, teachers, and students in the Richmond School District for their participation in the study.

\section{Authors' affiliations \\ H A McKay, L MacLean, K MacKelvie-O'Brien, P Janssen, K M Khan, University of British Columbia, Vancouver, BC, Canada \\ M Petit, Department of Kinesiology, University of Minnesota, Minneapolis, MN, USA \\ T Beck, Johns Hopkins University, Baltimore, MD, USA}

Financial support for this study was provided by the Canadian Institutes of Health Research and the Michael Smith Foundation for Health Research.

Competing interests: none declared 


\section{REFERENCES}

1 Bailey DA, Faulkner RA, McKay HA. Growth, physical activity, and bone mineral acquisition. In: Holloszy JO, ed. Exercise and sport sciences reviews. Baltimore, MD: Williams \& Wilkins, 1996:233-66.

2 Glastre C, Braillon P, David L, et al. Measurement of bone mineral content of the lumbar spine by dual energy $\mathrm{x}$-ray absorptiometry in normal children: correlations with growth parameters. J Clin Endocrinol Metab 1990;70:1330-3.

3 Theintz G, Buchs B, Rizzoli R, et al. Longitudinal monitoring of bone mass accumulation in healthy adolescents: evidence for a marked reduction after 16 years of age at the levels of lumbar spine and femoral neck in female subjects. $J$ Clin Endocrinol Metab 1992;75:1060-5.

4 Bonjour JP, Theintz G, Buchs B, et al. Critical years and stages of puberty for spinal and femoral bone mass accumulation during adolescence. $J$ Clin Endocrinol Metab 1991;73:555-63.

5 Khan KM, McKay HA, Kannus P. Physical activity and bone health Champaign, IL: Human Kinetics, 2001

6 MacKelvie KJ, Khan KM, McKay HA. Is there a critical period for bone response to weight-bearing exercise in children and adolescents? A systematic review. Br J Sports Med 2002;36:250-7.

7 Kannus P, Haapasalo H, Sankelo M, et al. Effect of starting age of physical activity on bone mass in the dominant arm of tennis and squash players. Ann Intern Med 1995; 123:27-31.

8 Seeman E. An exercise in geometry. J Bone Miner Res 2002;17:373-80.

9 Bass SL. The prepubertal years: a uniquely opportune stage of growth when the skeleton is most responsive to exercise? Sports Med 2000;30:73-8.

10 Jarvinen T, Kannus P, Sievanen H. Have the DXA-based exercise studies seriously underestimated the effects of mechanical loading on bone? J Bone Miner Res 1999;14:1634-5.

11 MacKelvie KJ, McKay HA, Khan KM, et al. A school-based exercise intervention augments bone accrual in early pubertal girls. J Pediatr 2001;139:501-8

12 MacKelvie KJ, McKay HA, Petit MA, et al. Bone mineral response to a 7 month randomized controlled, school-based jumping intervention in 121 prepubertal boys: associations with ethnicity and body mass index. J Bone Miner Res 2002; 17:834-44.

13 Petit MA, McKay HM, MacKelvie KJ, et al. A randomized school-based jumping intervention confers site and maturity specific benefits on bone structural properties in girls: a hip structural analysis (HSA) study. J Bone Miner Res 2002;17:363-72.

14 MacKelvie KJ, Khan KM, Petit MA, et al. A school-based exercise intervention elicits substantial bone health benefits: a 2 -year randomized controlled trial in girls. Pediatrics 2003;112:e447.
15 MacKelvie KJ, Petit MA, Khan KM et al. Bone mass and structure are enhanced following a 2-year randomized controlled trial of exercise in prepubertal boys. Bone 2004;34:755-64.

16 McKay HA, Macdonald H, Reed KE, et al. Exercise interventions for health: time to focus on dimensions, delivery, and dollars. Br J Sports Med 2003;37:98-9.

17 McKay HA, Petit MA, Schutz RW, et al. Augmented trochanteric bone mineral density after modified physical education classes: a randomized school-based exercise intervention study in prepubescent and early pubescent children. J Pediatr 2000;136:156-62.

18 Fuchs RK, Bauer JJ, Snow CM. Jumping improves hip and lumbar spine bone mass in prepubescent children: a randomized controlled trial. J Bone Miner Res 2001; 16:148-56.

19 Bradney M, Pearce G, Naughton G, et al. Moderate exercise during growth in prepubertal boys: changes in bone mass, size, volumetric density, and bone strength: a controlled prospective study. J Bone Miner Res 1998;13:1814-21.

20 Morris FL, Naughton GA, Gibbs JL, et al. Prospective 10-month exercise intervention in pre-menarcheal girls: positive effects on bone and lean mass. $J$ Bone Miner Res 1997; 12:1453-62.

21 Robling AG, Burr DB, Turner CH. Recovery periods restore mechanosensitivity to dynamically loaded bone. J Exp Biol 2001;204:3389-99.

22 Umemura Y, Ishiko T, Yamauchi T, et al. Five jumps per day increase bone mass and breaking force in rats. J Bone Miner Res 1997;12:1480-5.

23 McKay HA, Tsang GC, Heinonen A, et al. Ground reaction forces associated with an effective elementary school based jumping intervention. $\mathrm{Br} J$ Sports Med 2005;39:10-4

24 Tanner JM. Fetus into man. Cambridge: Harvard Press, 1978.

25 CSEP. Canadian physical activity and fitness lifestyle appraisal manual. Ottawa, Canada: Canadian Society for Exercise Physiology, 1998.

26 Barr SI. Associations of social and demographic variables with calcium intakes of high school students. J Am Diet Assoc 1994;94:260-6, 269.

27 Crocker PRE, Bailey DA, Faulkner RA, et al. Measuring general levels of physical activity: preliminary evidence for the physical activity questionnaire for older children. Med Sci Sports Exerc 1997;29:1344-9.

28 Kowalski KC, Crocker PRE, Faulkner RA. Validation of the physical activity questionnaire for older children. Pediatr Exerc Sci 1997;9:174-86.

29 Bailey DA, McKay HA, Mirwald RL, et al. A six year longitudinal study of the relationship of physical activity to bone mineral accrual in growing children: the University of Saskatchewan bone mineral accrual study. J Bone Miner Res 1999;14:1672-9.

30 Hologic. Model QDR-4500 user's guide. Waltham, MA: Hologic, Inc, 1996.

31 Beck TJ, Ruff CB, Warden KE, et al. Predicting femoral neck strength from bone mineral data: a structural approach. Invest Radiol 1990;25:6-18.

32 Heinonen A, Sievanen H, Kannus P, et al. High-impact exercise and bones of growing girls: a 9-month controlled trial. Osteoporosis Int 2000;11:1010-7. 